\title{
Perspectives on "Good" in Blockchain for Good
}

\author{
Glenn Parry ${ }^{1 *}$ and John Collomosse ${ }^{2}$ \\ ${ }^{1}$ Centre of Digital Economy, Surrey Business School, and Centre for the Decentralised Digital Economy, University of Surrey, \\ Guildford, United Kingdom, ${ }^{2}$ Centre for Vision, Speech and Signal Processing (CVSSP), Department of Electrical and Electronic \\ Engineering, and Centre for the Decentralised Digital Economy, University of Surrey, Guildford, United Kingdom
}

OPEN ACCESS

Edited by:

Christopher Clack,

University College London,

United Kingdom

Reviewed by:

Meghana Kshirsagar, University of Limerick, Ireland

Olinga Taeed,

Centre for Citizenship, Enterprise and

Governance, United Kingdom

${ }^{*}$ Correspondence:

Glenn Parry

g.parry@surrey.ac.uk

Specialty section: This article was submitted to Blockchain for Good, a section of the journal

Frontiers in Blockchain

Received: 22 September 2020 Accepted: 08 December 2020

Published: 27 January 2021

Citation:

Parry G and Collomosse J (2021)

Perspectives on "Good" in Blockchain for Good. Front. Blockchain 3:609136. doi: 10.3389/fbloc.2020.609136
Blockchain projects have been developed to extend the reach of distributed ledger technology (DLT) beyond cryptocurrency to achieve "good" in the world. Such projects may make a claim for moral, ethical, and responsible intent, but many researchers have not critically examined what good means in context. The concept of good has been debated for centuries and whilst we will not conclude the argument, we should engage in the discourse. We propose the idea that exploration across micro, meso, and macro levels of value creating ecosystems is needed. The implications, both practical and theoretical, of the use of blockchain for good require analysis. As the ambition for blockchain innovations to transform society for the better becomes practical reality, understanding of such change will come from transdisciplinary researchers able to bridge knowledge of social and technical systems.

Keywords: blockchain, distributed ledger technologies, blockchain for good, privacy, trust, value

\section{INTRODUCTION}

Research examining distributed ledger technology (DLT) has often claimed that technology creates a trusted system that can create good in the world (Kewell et al.,2017; Ducrée et al., 2020; Fard Bahreini et al., 2020). A decentralised digital economy (DDE) that gives individuals control over their own data could challenge the current digital oligopoly (Gilder, 2018; Manski, 2020). Though history provides caution; previously the internet was thought of as a means to subvert incumbents by bringing consumers and firms closer together (Nuccio and Guerzoni, 2019). In this article, we present a perspective on blockchain for good. We challenge researchers to question fundamental assumptions made in the discourse on what good, trust, and privacy mean within a DLT context. Through engaging in the ontological and epistemological considerations of good, researchers and practitioners may consider how value is cocreated with individuals, organisations, and society. Without such detailed consideration, a DDE may duplicate the current data paradigm with different dominant actors (Pass and Shi, 2017). 


\section{A Vison for Decentralisation}

Blockchain was heralded by many as a new technology that would save us all. Reports stated that blockchain would "help with the refugee crisis" crisis"3,4,5,6 and "eradicate poverty"7,8,9. These were bold claims for what is fundamentally a technology that creates a list that is difficult to change. Distributed ledger technologies may be the seed for change, but they are embedded in ecosystems that may lead to paradigm shifts. Such claims were too narrowly focused upon one level of a broader sociotechnical system. They miss the multiple levels of interaction and value cocreation between and across levels in a system that impact value creation (Chandler and Vargo, 2011; Akaka and Parry, 2019). A broader transdisciplinary perspective (Jantsch, 1970), integrating knowledge from across disciplines, is required to understand and unlock the potential of DLT.

Digitalisation is changing society, providing new technologies that change the way we work, shop, collaborate, and create value. The first wave of digital growth started with many innovative organisations, but over time this has resulted in a small number of dominant monolithic institutions. The next wave of digital economy is developing, driven by artificial intelligence (AI), internet of things (IoT) (Parry et al., 2016), and distributed systems that shift digital boundaries (Mulligan et al., 2020). The future is always in a state of becoming, and there is an opportunity for a shift from the classical economic models of dominant single large firms towards decentralised infrastructures, controlled by many more parties. Decentralised governance mechanisms seek to mitigate potential drawbacks of centralised platforms where data controllers misappropriate and expropriate user data and value (Catalini and Gans, 2020).

Digital technology has come to underpin society, yet it is not controlled by society. Governments have failed to keep pace with innovation and failed to adequately govern. An opportunity is presented by technology to implement a new form of digital governance that empowers citizens (Zwitter and Hazenberg, 2020). A dynamic and decentralised peer-to-peer economy can be built upon distributed data sharing infrastructures, such as distributed ledger technologies (DLT). In such structures, data is freed from the silos of the large firms and becomes fluid and able to create value for the individual and the organisations who help

${ }^{1}$ https://www.forbes.com/sites/rogerhuang/2019/01/27/how-blockchain-can-helpwith-the-refugee-crisis/

${ }^{2}$ https://www.weforum.org/agenda/2018/06/three-ways-blockchain-change-refugeeslives/

${ }^{3}$ https://medium.com/kingsland/how-blockchain-is-solving-the-world-hunger-crisis$8 \mathrm{~b} 2 \mathrm{f} 438 \mathrm{f} 2 \mathrm{a} 35$

${ }^{4}$ https://www.unece.org/fileadmin/DAM/cefact/OtherMeetings/2018/BlockChain ForTradeFacilitation_Geneva/03_GiovanniPio-Blockchain.pdf

${ }^{5}$ https://www.forbes.com/sites/forbestechcouncil/2019/12/26/how-blockchain-canaddress-food-waste-and-hunger/\#6a0554dc2dba

${ }^{6} \mathrm{https} / / /$ www.mhlnews.com/global-supply-chain/article/22054984/one-mans-trashhow-blockchain-can-target-food-waste-to-help-end-world-hunger

${ }^{7}$ https://www.marketlinks.org/post/how-blockchain-can-eradicate-poverty-developingcountries

${ }^{8}$ https://www.wsj.com/articles/how-blockchain-can-end-poverty-1516925459

${ }^{9} \mathrm{https}: / /$ denver-south.com/can-blockchain-technology-be-used-to-end-poverty/ them create and share it. A shift in power from the tech giants to the individual would be facilitated by decentralised autonomous organisations (DAOs) (Gilder, 2018; Morrison et al., 2020) and other decentralised platforms that promote data fluidity (and so, creation of value) ensuring user agency over that data and its use.

DAOs open the way to build a future decentralised digital economy (DDE), where data is controlled by the people who create it. People and organisations will be in more direct connection, trading data and meta-data insights. Such relationships require frictionless digital interactions and autonomous services that are not reliant upon traditional intermediaries. New forms of trust will be cocreated within DAO ecosystems.

The DDE is characterised by relationships with products and service providers that, though once long term, may now be fleeting. Methods of production and delivery reflect this short termism, with systems built on opportunistic engagements. The "gig economy" has been built on data exchanges, driven data exchange between a diaspora of digital identities cocreating value through new business models. Such models are less constrained by physical geographies, often scaled and mirrored around the world. The digital part of the businesses is devoid of sentiment: algorithms maximising financial gain. The digital is not isolated, but forms part of broader sociotechnical systems and their implications for society are yet to fully unfold. Research needs to be done to capture both the benefits and the drawbacks-to really understand the meaning of value and how it is created or diminished in the DDE, and to consider what is good. Such a sociotechnical research ethos underpins several European initiatives such as the EU "Blockchain for Social Good" call and UK-led initiatives such as DECaDE, a UKRI funded Centre studying the DDE.

\section{Consideration of Good}

"Blockchain for Good" describes the journal section in Frontiers in Blockchain with an explicit moral, ethical, and responsible intent. To date too few authors have examined what "good" and "value" actually mean in relation to the technology application, and for whom value is created and why (see for example Kim and Zetlin-Jones, 2019; Manski and Bauwens, 2020; Zambrano, 2020). Most assume that the application is inherently good either because of their area of study, e.g., aid flows, human rights, etc., or simply because the application is in a nonfinancial area. We have seen DLT applications that provide identity, particularly in the Global South (Wang and De Filippi, 2020). The value of such systems appears to be mainly for the provider, making it possible to identify individuals so they can be more easily processed. It is unclear if individuals consent is sought before their details are captured, and though the creators of such systems propose they create valuable support for migrants, it appears that most of the value is for the aid provider. Individual migrants are often escaping situations corrupted by institutions and seek anonymity, which may be threatened by malicious actors just because of the existence of such records. How good an innovation is depends upon context and perspective.

Value can be considered as a measure of "goodness," and how "good" or valuable something may be has been debated for 
centuries (Ng, 2014). Plato (360 B.C.E) discussed value in The Republic, proposing that value may be intrinsic if a thing is good to have in and of itself, or extrinsic if it enables you to achieve or obtain something good (Lee, 2007). Central to debates around value is whether "good" can be a property of something, that good is objective and therefore some things are intrinsically good, or if goodness is subjective and determined by the individual in context. Moore suggested that goodness could not be naturally occurring; something could only be good if someone perceived it to be good (Moore, 1993). Hence, good or value may be considered as subjectively evaluated. The properties individuals ascribe to that which they value are often common, for example, truth, beauty, harmony, peace, security, etc. (Frankena, 1965). Whilst different lists have been created, commonality between them points back towards intrinsic value. Frankena (1965) proposes that truth or knowledge may be cold and valueless; rather, it is the experience of them that may lead to them being of value, and hence good is again extrinsically determined.

However, one wishes to consider "good"; it is important to have made such a consideration and described how good or value is created by the offer and for whom. Sharing the value that data can provide equitably within a DDE requires consideration of the service ecosystem; the system that creates value. A service ecosystem perspective provides a holistic view of the value created by an offer, extending beyond the boundary of the firm to include all network actors who interact in value creating activities (Vargo and Lusch, 2011; Lusch and Nambisan, 2015). Actors are social and economic resource integrators and may include individuals, households, firms, and nations (Vargo and Lusch, 2008). A service ecosystems view emphasises interactions at multiple levels: dyadic relationships occur at a micro level, such as actor-to-actor relationships; the meso level represents midrange interactions between industries or communities; finally, at the macro level, cultural, policy, and wider social structures are considered (Vargo and Lusch, 2016; Akaka and Parry, 2019).

A question arises as to where DLT technologies are placed in a service ecosystem. A system is a lens through which we can perceive value, but the levels of context and value are nested, evolving conceptualisations of interactions which cocreate value (Chandler and Vargo, 2011). Value creating encounters between people, organisations, governments, and cultural structures is well theorised. In considering blockchain for good we are particularly interested in the process through which distributed ledgers act within a system to create value and hence good in the world. Lusch and Nambisan (2015) argue for the inclusion of inanimate agents in the definition of actors. They argue that the design and designer of an inanimate agent have been influenced by macrostructures, and subsequently the inanimate agent acts to reinforce social structures, so perhaps they are micro-level or even mesolevel phenomenon. However, practice is ahead of theory, and research has yet to explore if digitised autonomous capabilities are agents and can be considered as resource integrators (Porter and Heppleman, 2014), at which level they are most appropriately placed, and the way such technologies have impact across the ecosystem.
The socioeconomic factors driving adoption of technologies underpinning the DDE are poorly understood, leading to further areas of analysis: how can we represent and communicate the values of decentralised infrastructures and sustainably incentivise engagement to ensure a scalable platform for the DDE? How can we balance the needs of data hungry AI services vs. those of individuals and organisations with regard to agency over data and digital assets? What does good governance look like in a DDE, and can regulation ensure safety and stability for a DDE?

\section{Issues of Trust and Privacy}

Proponents of DLT claim that it provides an architecture that enables it to be trust-free technology, a so-called trustless system (Beck et al., 2016; Werbach, 2019). Saying DLT is trustless is an overstatement of what the technology, as part of a service system, is able to deliver (Hawlitschek et al., 2018). Any service will require their users to trust the service provider (organisational trust) and the extended ecosystem of partners and providers, many of whom will be unknown and unseen by the client (system-level trust) (Sekhon et al., 2013). Rather than trusting conventional institutions, in blockchain systems individuals cede authority to algorithms to provide information that is considered to be true and to direct action (Lustig and Nardi, 2015). But can trust be fully replaced by an algorithm or does there remain a need for a representative organisation-an institution whose role is the support and maintenance of that algorithm? For example, blockchain was recently trialled by several national archives of sovereign states as a means for mutually underwriting the integrity (rendering "tamper-evident") of their digital records. Leveraging a decentralized platform enabled a shift from an institutional trust model to a technological underscoring of trust; effectively the archives' integrity was underwritten by a consortium of archives that collectively maintained the blockchain (Collomosse et al., 2018; Bui et al., 2020). Yet that consortium might be considered a maintaining institution or at least a federation of institutions tasked with perpetuating participation in the blockchain consensus.

At the heart of the claims for trustlessness is perhaps not the removal of trust, but rather a shift in where an individual's trust is placed. In decentralised systems the very notion of decentralisation and the removal of a central authority creates a tension as it may not be clear who holds design authority over the code and the mechanism of how they would be trusted. Practically, the answer involves examination of the various DLT architectures and any consensus mechanisms they may employ, each of which has some shortcomings, e.g., the 2016 attack on the Ethereum blockchain and collapse of its Decentralized Autonomous Organization (Risius and Spohrer, 2017). Trust in DLT is further challenged when systems are specifically designed for privacy, making partners in the network anonymous. There are important questions about trust in the data. Data stored or verified by a ledger may be of poor quality or lack accuracy (Thompson, 2019), due to both fraud and human input error (O'Leary, 2017). Blockchain has been described as the "trust machine," but this "halo of truth" may lead to a "lack of questioning of the data" (Rogerson and Parry, 2020). There is a need to develop technical understanding and confidence in 
individuals, so they work with the technology, neither directly accepting or rejecting data, but questioning what it says and why (Brynjolfsson and McAfee, 2012).

In the shadow of the recent cryptocurrency boom and bust, DAOs have suffered a credibility crisis that may impact their adoption as a trusted technology. The cycle fuelled numerous token sales through "Initial Coin Offerings" (ICOs) in which financial investments, mediated by cryptocurrencies, encouraged the purchase of stakes in DAOs. The significant efforts made by $\mathrm{DAO}$ founders to promote, and in many cases overpromise on, such investments have led to reputational damage in DAOs and the broader field of DLT technology, impeding adoption.

Privacy covers a broad range of topics including data collection, processing, and dissemination (Solove, 2007). Whilst the judicial definition of privacy is the right to be left alone (Warren \& Brandeis, 1890), more appropriate definitions for DLT contexts include appropriate flow and access to information (Nissenbaum, 2009; Xu et al., 2012) and differential privacy via mathematical proofs that metricise the interaction of databases to limit interaction (Doudalis, 2017). Taking recurrent elements of privacy definitions, we may understand data privacy as "control over provision of appropriate access to personal information” (Hsu et al., 2020).

Decentralisation can be a way of providing greater privacy in context, as part of a process which gives individuals greater control over who can access their personal data. Though DLT is often presented as privacy-preserving, technology is always vulnerable to the hacking threat and individuals remain pseudonymous so long as no link is made between identity and a wallet address. The EU General Data Protection Regulation (GDPR) provides the governing principles of data protection and processing and deems privacy a human right to be protected regardless of economic impact. Article 17 of GDPR states that an individual has the right to be forgotten. If the identity of an individual on a DLT was revealed and that individual demanded to be "forgotten," there is potentially an existential threat to the blockchain. Forgetting could require editing or removing data, undermining the DLT ethos and potentially requiring the deletion of the ledger-if that is even

\section{REFERENCES}

Akaka, M. A., and Parry, G. (2019). Value-in-Context: an exploration of the context of value and the value of context. in Handbook of service science., Editors P. P. Maglio, C. A. Kieliszewski, J. C. Spohrer, K. Lyons, L. Patricio, and Y. Sawatani, Vol. II, 457-477. doi:10.1007/978-3-319-98512-1_20

Beck, R., Stenum Czepluch, J., Lollike, N., and Malone, S. (2016). "Blockchain - the gateway to TRUST-FREE cryptographic transactions cryptographic economic systems and the "internet of things" in Twenty-Fourth European Conference on Information Systems (ECIS), Istanbul, Turkey, June 12-15, 2016

Brynjolfsson, E., and McAfee, A. (2012). Winning the race with ever-smarter machines. MIT Sloan Manag. Rev. 53 (2), 53-60.

Bui, T., Cooper, D., Collomosse, J., Bell, M., Green, A., Sheridan, J., et al. (2019). ARCHANGEL: tamper-proofing video archives using temporal content hashes on the blockchain. IEEE/CVF conference on computer vision and pattern recognition. 1st workshop on AI and blockchain. possible-creating a potential paradox of privacy in distributed public ledgers. For this reason, many DLT implementations rely upon the distributed ledger to underpin the integrity of an otherwise mutable data store such as a cloud-based data lake (Franceschi et al., 2018). Trust in data is derived from transparency and nonrepudiation (evidenced, for example, by hashes or "fingerprints" of data) whilst accommodating its future redaction (Collomosse et al., 2018; Bui et al., 2019; Yang et al., 2020). This and other issues with contemporary DLT (principally, scalability) point to DLT, not as a storage technology for immutable data, but as a supportive technology to underwrite the integrity and promote trust in data.

\section{Future of Blockchain for Good}

To explore the reconceptualization of value and what it means to achieve good in the DDE beyond cryptocurrency requires determination of what constitutes goodness, fairness, and worth in context and how these are tied to equality in a digital economy. The technology is part of a broader service ecosystem, where actors, agents, and institutions cocreate value. Going forwards, whilst our interest is the application of DLT, the value that the technology creates and the challenges to adoption will require researchers to examine the sociotechnical system. Such research will require transdisciplinarity to shatter technological and socioeconomic barriers to a sustainable, fair, and prosperous DDE.

\section{DATA AVAILABILITY STATEMENT}

The original contributions presented in the study are included in the article/Supplementary Material; further inquiries can be directed to the corresponding author.

\section{AUTHOR CONTRIBUTIONS}

GP and JC coauthored the article drawing upon the themes from DECADE: Centre for the Decentralised Digital Economy.

Bui, T., Cooper, D., Collomosse, J., Bell, M., Green, A., Sheridan, J., et al. (2020). Tamper proofing video with hierarchical attention autoencoder on blockchain. IEEE Trans. Multimedia 22 (11). doi:10.1109/TMM.2020.2967640

Catalini, C., and Gans, J. S. (2020). Some simple economics of the blockchain. Commun. ACM. 63 (7), 80-90. doi:10.1145/3359552

Chandler, J. D., and Vargo, S. L. (2011). Contextualization and value-in-context: how context frames exchange. Market. Theor. 11 (1), 35-49. doi:10.1177/ 1470593110393713

Collomosse, J., Bui, T., Brown, A., Sheridan, J., Green, A., Bell, M., et al. (2018). ARCHANGEL: trusted archives of digital public documents. Proceedings ACM document engineering conference (DocEng).

Doudalis, S. (2017). Towards privacy definition for hybrid sensitivity data. Irvine, CA: University of California.

Ducrée, J., Etzrodt, M., Gordijn, B., Gravitt, M., Bartling, S., Walshe, R., et al. (2020). Blockchain for organizing effective grass-roots actions on a global commons: saving the planet. Front. Blockchain. 3, 33. doi:10.3389/fbloc.2020. 00033 
Fard Bahreini, A., Collomosse, J., Seidel, M. D., Sotoudehna, M., and Woo, C. (2020). Distributing and democratizing insitutional power through decentralization. Chapter 5, In Building decentralized trust: multidisciplinary perspectives on the design of blockchains and distributed ledgers. Springer.

Franceschi, M., Morelli, D., Plans, D., Brown, A., Collomosse, J., Coutts, L., et al. (2018). ComeHere: exploiting ethereum for secure sharing of healthcare data. European conference on parallel processing [Euro-Par 2018]: parallel processing workshops. Lect. Notes Comput. Sci. Cham: Springer 11338, 585-596. doi:10.1007/978-3-030-10549-5_46

Frankena, W. K. (1965). Ethics (foundations of philosophy., 4th ed. New Jersey: Prentice-Hall

Gilder, G. (2018). Life after google: the fall of big data and the rise of the blockchain economy, 1st edn. Gateway Ed.

Hawlitschek, F., Notheisen, B., and Teubner, T. (2018). The limits of trust-free systems: a literature review on blockchain technology and trust in the sharing economy. Electron. Commer. Res. Appl. 29, 50-63. doi:10.1016/j.elerap.2018.03.005

Hsu, M., Parry, G., Kharlamov, A., and Ng, I. C. L. (2020). "Managing personalization-privacy paradox of digital services: a systematic literature review." in 6th Competitive Advantage in the Digital Economy (CADE) Forum, Venice, Italy, May 20-22, 2019

Jantsch, E.. (1970). Inter- and transdisciplinary University: A aystems approach to education and innovation. Policy Sciences. 1, 403-428. doi:10.1007/BF00145222

Kewell, B., Adams, R., and Parry, G. (2017). Blockchain for good? Strat. Change. 26(5), 429-437. doi:10.1002/jsc.2143

Kim, T. W., and Zetlin-Jones, A. (2019). The ethics of contentious hard forks in blockchain networks with fixed features. Front. Blockchain. 2, 9. doi:10.3389/ fbloc.2019.00009

Lee, D. (2007). The republic. 3rd Edn. London, United Kingdom: Penguin Classics.

Lusch, R. F., and Nambisan, S. (2015). Service innovation: a service-dominant logic perspective. MIS Q. 39(1), 155-175. doi:10.25300/MISQ/2015/39.1.07

Lustig, C., and Nardi, B. (2015). "Algorithmic authority: the case of bitcoin," in 2015 48th Hawaii international Conference on system sciences, Kauai, HI, January $5-8,2015,743-752$.

Manski, S., and Bauwens, M. (2020). Reimagining new socio-technical economics through the application of distributed ledger technologies. Front. Blockchain. 2, 29. doi:10.3389/fbloc.2019.00029

Manski, S. (2020). Distributed ledger technologies, value accounting, and the self sovereign identity. Front. Blockchain. 3, 29. doi:10.3389/fbloc.2020.00029

Moore, G. E. (1993). Principa ethica. Cambridge, UK: Cambridge University Press.

Morrison, R., Mazey, N. C. H. L., and Wingreen, S. C. (2020). The DAO controversy: the case for a new species of corporate governance? Front. Blockchain. 3, 25. doi:10.3389/fbloc.2020.00025

Mulligan, C., Godsiff, P., and Brunelle, A. (2020). Boundary spanning in a digital world: the case of blockchain. Front. Blockchain. 3, 37. doi:10.3389/fbloc.2020.00037

$\mathrm{Ng}$, I. C. L. (2014). Creating new markets in the digital economy: value and worth. Cambridge, UK: Cambridge University Press.

Nissenbaum, H. (2009). Privacy in context: technology, policy, and the integrity of social life. Palo Alto, CA: Stanford University Press.

Nuccio, M., and Guerzoni, M. (2019). Big data: hell or heaven? Digital platforms and market power in the data-driven economy. Competition and Change. 23, 312-328. doi:10.1177/1024529418816525

O’Leary, D. E. (2017). Configuring blockchain architectures for transaction information in blockchain consortiums: the case of accounting and supply chain systems. Intell. Syst. Account. Finance Manag. 24 (4), 138-147. doi:10.1002/isaf.1417

Parry, G., Brax, S. ., Maull, R., and Ng, I. (2016). Visibility of consumer context: improving reverse supply with internet of things data. Supply Chain Manag.: Int. J. 21 (2), 228-244. doi:10.1108/SCM-10-2015-0386
Pass, R., and Shi, E. (2017). "FruitChains: a fair blockchain." in ACM symposium on principles of distributed computing, 2016, Washington, DC, (New York, NY, ACM), 315-324.

Porter, M. E., and Heppleman, J. E. (2014). How smart, connected products are transforming competition. Harv. Bus. Rev. 92 (11), 64-88.

Risius, M., and Spohrer, K. (2017). A blockchain research framework. Bus. Inform. Syst. Eng. 59, 385-409. doi:10.1007/s12599-017-0506-0

Rogerson, M., and Parry, G. C. (2020). Blockchain: case studies in food supply chain visibility. Supply Chain Manag. 25 (5), 601-614. doi:10.1108/SCM-082019-0300

Sekhon, H., Roy, S., Shergill, G., and Pritchard, A. (2013). Modelling trust in service relationships: a transnational perspective. J. Serv. Market. 27 (1), 76-86. doi:10. 1108/08876041311296392

Solove, D. J. (2007). I've got nothing to hide and other misunderstandings of privacy. San Diego L. Rev., 44, 745.

Thompson, C. (2019). Opportunities and challenges in applying distributed ledger technologies in global supply chains for social good. Front. Blockchain., 2, 11. doi:10.3389/fbloc.2019.00011

Vargo, S. L., and Lusch, R. F. (2008). Service-dominant logic: continuing the evolution. J. Acad. Market. Sci. 36 (1), 1-10. doi:10.1007/s11747-007-0069-6

Vargo, Stephen. L., and Lusch, R. F. (2011). It's all B2Band beyond: toward a systems perspective of the market. Ind. Market. Manag. 40 (2), 181-187. doi:10. 1016/j.indmarman.2010.06.026

Vargo, Stephen. L., and Lusch, R. F. (2016). Institutions and axioms: an extension and update of service-dominant logic. J. Acad. Market. Sci. 44, 5-23. doi:10. 1007/s11747-015-0456-3

Wang, F., and De Filippi, P. (2020). Self-sovereign identity in a globalized world: credentials-based identity systems as a driver for economic inclusion. Front. Blockchain. 2, 28. doi:10.3389/fbloc.2019.00028

Warren, S. D., and Brandeis, L. D. (1890). The right to privacy. Harv. Law Rev., 193-220.

Werbach, K. (2019). Summary: Blockchain, The Rise of Trustless Trust? Available at:https://repository.upenn.edu/cgi/viewcontent.cgi?article $=1002 \&$ context $=$ pennwhartonppi_bschool

Xu, H., Teo, H.-H., Tan, B. C. Y., and Agarwal, R. (2012). Effects of individual selfprotection, industry self-regulation, and government regulation on privacy concerns: a study of location-based services. Inf. Syst. Res. 23 (4), 1342-1363. doi:10.1287/isre.1120.0416

Yang, Y., Cooper, D., Collomosse, J., Dragan, C., Manulis, M., Briggs, et al. (2020). TAPESTRY: a decentralized service for trusted interaction online. IEEE Trans. Serv. Comput. doi:10.1109/TSC.2020.2993081

Zambrano, R.. (2020). Taming the beast: harnessing blockchains in developing country governments. Front. Blockchain. 2, 27. doi:10.3389/fbloc.2019.00027

Zwitter, A., and Hazenberg, J. (2020). Decentralized network governance: blockchain technology and the future of regulation. Front. Blockchain. 3, 12. doi:10.3389/fbloc.2020.00012

Conflict of Interest: The authors declare that the research was conducted in the absence of any commercial or financial relationships that could be construed as a potential conflict of interest.

Copyright $\odot 2021$ Parry and Collomosse. This is an open-access article distributed under the terms of the Creative Commons Attribution License (CC BY). The use, distribution or reproduction in other forums is permitted, provided the original author(s) and the copyright owner(s) are credited and that the original publication in this journal is cited, in accordance with accepted academic practice. No use, distribution or reproduction is permitted which does not comply with these terms. 